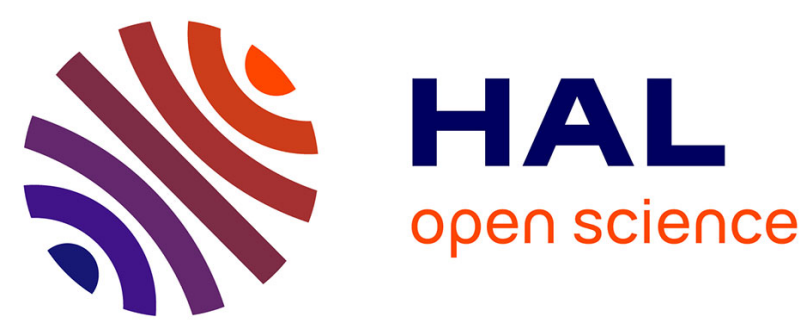

\title{
Growth of InP in a Novel Remote-Plasma MOCVD Apparatus: an Approach to Improve Process and Material Properties
}

\author{
G. Bruno, P. Capezzuto, M. Losurdo
}

\section{- To cite this version:}

G. Bruno, P. Capezzuto, M. Losurdo. Growth of InP in a Novel Remote-Plasma MOCVD Apparatus: an Approach to Improve Process and Material Properties. Journal de Physique IV Proceedings, 1995, 05 (C5), pp.C5-481-C5-488. 10.1051/jphyscol:1995555 . jpa-00253917

\section{HAL Id: jpa-00253917 https://hal.science/jpa-00253917}

Submitted on 1 Jan 1995

HAL is a multi-disciplinary open access archive for the deposit and dissemination of scientific research documents, whether they are published or not. The documents may come from teaching and research institutions in France or abroad, or from public or private research centers.
L'archive ouverte pluridisciplinaire HAL, est destinée au dépôt et à la diffusion de documents scientifiques de niveau recherche, publiés ou non, émanant des établissements d'enseignement et de recherche français ou étrangers, des laboratoires publics ou privés. 


\title{
Growth of InP in a Novel Remote-Plasma MOCVD Apparatus: an Approach to Improve Process and Material Properties
}

\author{
G. Bruno, P. Capezzuto and M. Losurdo \\ Centro di Studio per la Chimica dei Plasmi-CNR, Dipartimento di Chimica-Università di Bari-via Orabona, \\ 4-70126 Bari, Italy
}

\begin{abstract}
Remote plasma metalorganic chemical vapor deposition (RP-MOCVD) technique, though relatively new, is becoming more and more important in the processing of the III-V semiconductor materials and, specifically, of indium phosphide. So far different processes have been designed for (a) the cleaning of InP substrates to remove surface native oxide by reduction with $\mathrm{H}_{2}$ plasma and (b) the InP deposition under $\mathrm{PH}_{3}$ plasma preactivation. This paper deals with InP homoepitaxial growth by trimethylindium (TMI) and plasma preactivated $\mathrm{PH}_{3}$. Optical emission spectroscopy (OES) measurements evidence the presence of $\mathrm{PH}$ and $\mathrm{PH}_{2}$ radicals, and of $\mathrm{H}$-atoms in the plasma phase. Mass spectrometry (MS) sampling close to the growth surface reveals the presence of alchylphosphinc $\left(\left(\mathrm{CH}_{3}\right)_{2} \mathrm{PH}, \mathrm{CH}_{3} \mathrm{PH}_{2}\right)$, indium-phosphorus adduct and biphosphine $\left(\mathrm{P}_{2} \mathrm{H}_{4}\right)$, whose relative amounts depend on the growth conditions. Stoichiometric InP epilayers having good structure and morphology, and with a very high photoluminescence intensity are prepared under $\mathrm{PH}_{3}$ plasma preactivation, even at very low V/III ratio $(=20)$ and reduced temperature $\left(-550^{\circ} \mathrm{C}\right)$.
\end{abstract}

\section{INTRODUCTION}

Conventional MOCVD processes require high deposition temperature, to supply the activation energy for both gas phase and surface reactions, and high hydride $\left(\mathrm{PH}_{3}\right.$ or $\left.\mathrm{AsH}_{3}\right)$ flux to grow good quality III-V epitaxial layers [1]. Recently, innovative aspects have been introduced in the III/V MOCVD technology by using plasmas in remote configuration (RP) [2-4], which assures the absence of radiative damage to epitaxial layers. The plasma, as a secondary source of energy, removes kinetic limitations in the growth mechanism of phosphorus based semiconductors [5], and offers low temperature [6,7,8] and low V/III ratio processing [9], mainly by the pre-cracking of the thermally stable $\mathrm{PH}_{3}$. Plasma processes also offer a valid alternative to the use of the highly toxic $\mathrm{PH}_{3}$, by performing the in situ generation of $\mathrm{PH}_{3}$ through the ablation of red-phosphorus in $\mathrm{H}_{2}$ plasma [10-12]. Another plasma application of some importance for the III-V epitaxial growth is the in situ substrate cleaning process [13-14]. In fact, the presence of native oxides and carbon contaminations can impede the growth of epitaxial layers. These oxides can be removed by in situ $\mathrm{H}_{2}$ plasma treatment just before the film growth to yield clean surfaces.

Although there is a great worldwide interest in many research laboratorics on the use of plasma source in the MOCVD technologies, there has been little real progress toward the understanding of the plasma chemistry and of what really determines the surface processes. In reality, the difficulty in the investigation of RP-MOCVD processes lies in the large numbers of parameters to examine (pressure, r.f. power, gas flow, temperature) and in the lack of diagnostic techniques available on the MOCVD apparatus. Thus, the design of a new reactor architecture, allowing in situ diagnostics for both the process and the material, is essential. With respect 10 this, optical diagnostics such as reflectance difference spectroscopy (RDS) [15] and spectroscopic ellipsometry (SE) [16] (which are compatible with the reactive environment of MOCVD process) are well adapt to investigate the surface chemistries. Also. mass spectrometry (MS) is a powerful technique to investigate MOCVD processes, even though it has 
been utilized, mainly, for ex situ studies of chemistry [17,18] and kinetics [19] of the precursor decomposition.

In this paper, we report on the use of a low pressure RP-MOCVD apparatus, working at 2 torr, to grow InP epilayers from trimethylindium ( $\left.\mathrm{InMe}_{3}\right)$ and phosphine $\left(\mathrm{PH}_{3}\right)$. The $\mathrm{PH}_{3}$ and the carrier gas, $\mathrm{H}_{2}$, are plasma activated, while the organometallic $\operatorname{InMe}_{3}$ is not directly plasma dissociated, but is injected into the plasma downstream flow, where it interacts with plasma produced reactive species, such as $\mathrm{PH}_{\mathbf{X}}(\mathrm{x}=0-2)$ radicals and $\mathrm{H}$-atoms. Process diagnostic data, as obtained by mass spectrometry (MS) and optical emission spectroscopy (OES), are used to highlight the chemistry of the $\mathrm{PH}_{3}$ plasma precracking, also during the InP deposition process. From the InP deposition experiments we derive important informations regarding the growth kinetics and the correlations between chemistry at the growth surface and the material properties and morphology. The InP epilayers are characterized by structural (SEM, X-ray diffraction), and optical (photoluminescence, ellipsometry) techniques.

\section{EXPERIMENTAL}

The InP growth experiments were carried out in a home-made RP-MOCVD apparatus in which the plasma quartz tube is assembled on the stainless-steel MOCVD chamber, as schematized in fig. 1.

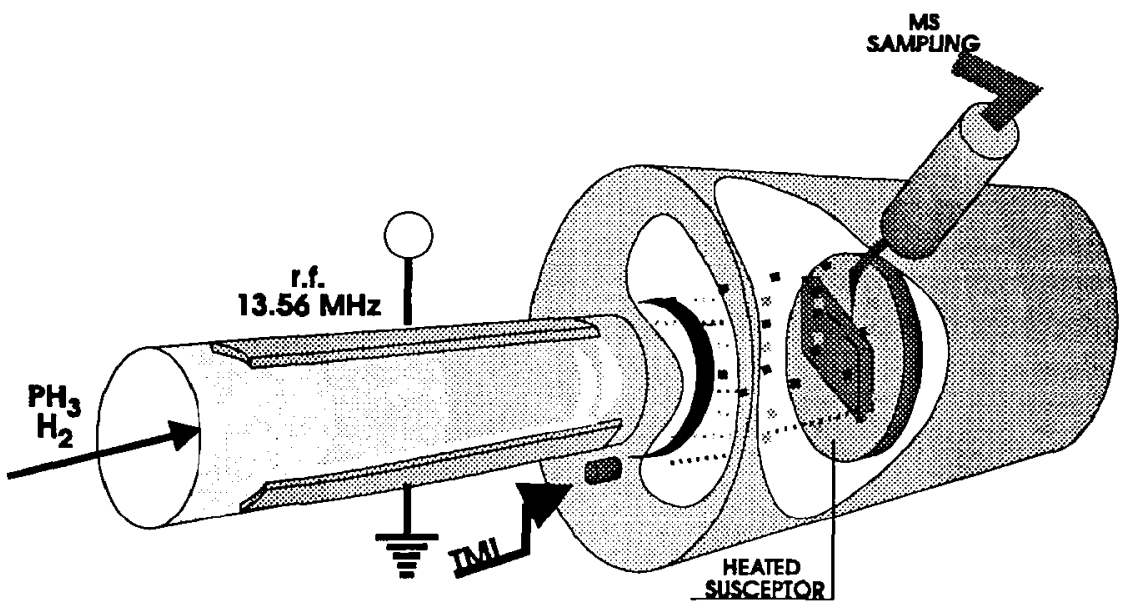

Figure 1: Assonometric scheme of the RP-MOCVD experimental apparatus.

The plasma, fed with $\mathrm{H}_{2}$ or $\mathrm{PH}_{3}-\mathrm{H}_{2}$ gas mixtures, is generated by supplying r.f. power (13.56 $\left.\mathrm{MHz}\right)$ to two semicircular external electrodes. Trimethylindium (TMI) is directly injected in the plasma downstream flow through a dispersal ring located in the MOCVD chamber at the end of the plasma tube. The substrate (Fe-doped semi-insulating (100)-oriented $\mathrm{InP}$ ) is mounted on a resistively-heated molybdenum susceptor whose temperature is controlled by a $\mathrm{K}$-thermocouple. The InP substrates are cleaned in isopropanol and then chemically etched in a $\mathrm{H}_{2} \mathrm{SO}_{4}: \mathrm{H}_{2} \mathrm{O}_{2}: \mathrm{H}_{2} \mathrm{O}$ (8:1:1) solution and immediately introduced into a load-lock chamber evacuated to $10^{-7}$ torr and then transferred into the MOCVD chamber. Some deposition experiments have been performed on InP substrates which are in situ cleaned by operating $\mathrm{H}_{2}$ plasma before the film growth [20]. InP growths are performed, with and without $\mathrm{PH}_{3}$ plasma activation (r.f. power $=20$ watt), at the pressure of 2 torr and at the total gas flow rate of $500 \mathrm{sccm}$. The V/III ratio and the substrate temperature have been changed in the range of 20 300 and $550^{\circ} \mathrm{C}-650^{\circ} \mathrm{C}$, respectively.

The study of the $\mathrm{PH}_{3}$ plasma preactivation has been performed by investigating the effect of r.f. power (5-60 watt) and of total gas flow rate $(3-800 \mathrm{sccm})$. 
Optical emission spectroscopy (OMA EG\&G-PAR) has been used to monitor the light emitted, in the range $200-800 \mathrm{~nm}$, from the active excited species present in the plasma phase. A quadrupolar mass spectrometer (VG-SPX-Elite 600) has sampled gases, through a $100 \mu \mathrm{m}$ orifice, in the boundary layer near the growth surface.

\section{RESULTS AND DISCUSSION}

\section{1 $\mathrm{PH}_{3}$ plasma preactivation}

Figure 2 shows the profiles of the $\mathrm{PH}_{3}$ decomposition and of its partial conversion to biphosphine, $\mathrm{P}_{2} \mathrm{H}_{4}$, and phosphorus, $\mathrm{P}_{4}$, ohtained by $\mathrm{MS}$ sampling, as a function of r.f. power and residence time of the $\mathrm{PH}_{3}-\mathrm{H}_{2}$ mixture in the plasma region. In the same figure, in addition to stable phosphorus products, $\mathrm{PH}$ radical and $\mathrm{H}$-atom density profiles, as derived by the actinometric approach of the OES measurements [12], are also reported.

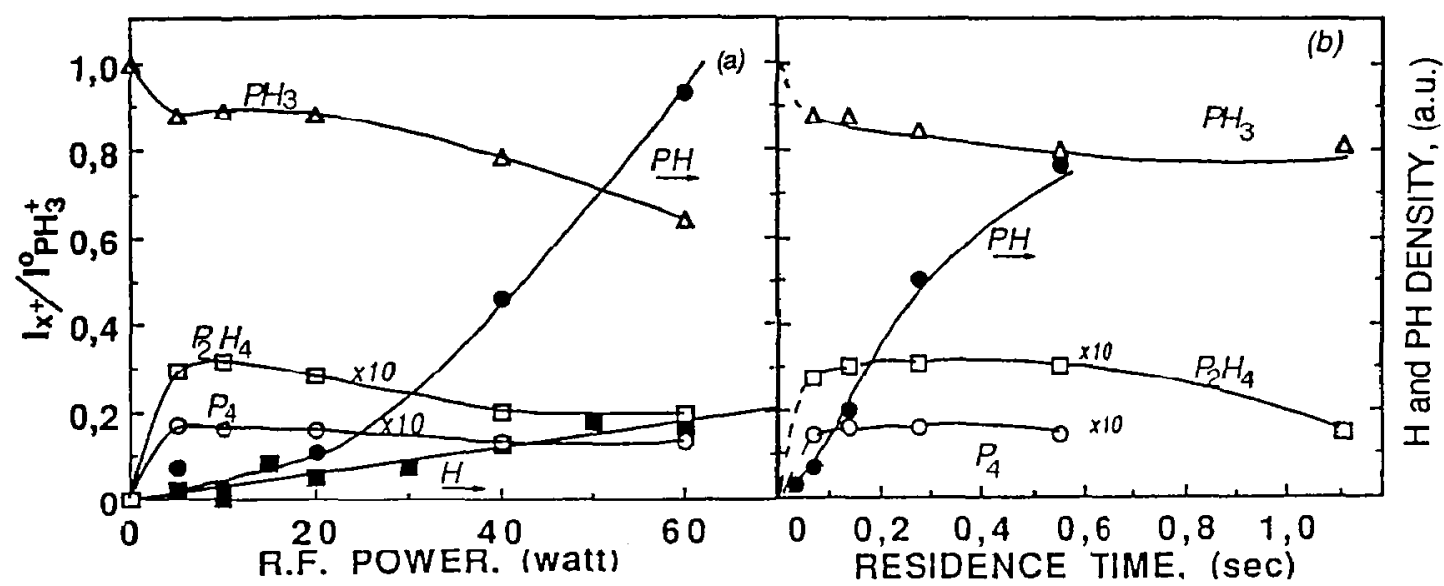

Figure 2: Effect of (a) r.f. power and (b) residence time on the gaseous reaction product distribution (left side) and on the $\mathrm{PH}$ radical and $\mathrm{H}$ atom density (right side) in $\mathrm{PH}_{3}-\mathrm{H}_{2}\left(\chi_{\mathrm{PH}_{3}}=0.03\right.$ ) plasma at $\mathrm{P}=2$ torr. (Other conditions for experiments (a) gas flow rate $=100 \mathrm{sccm}$ and (b) r.f. power $=20$ watt).

The fact that $\mathrm{PH}$ radical and $\mathrm{H}$-atom densities increase with r.f. power is related to the parallel increase of the electron density and, hence, to the effectiveness of processes which also govern the $\mathrm{PH}_{3}$ and $\mathrm{H}_{2}$ dissociation and, specifically, of the following reactions:

$$
\begin{aligned}
& \mathrm{PH}_{3}+\mathrm{e} \rightarrow \mathrm{PH}_{\mathrm{X}}+(3-\mathrm{x}) \mathrm{H}+\mathrm{e} \quad \mathrm{x}=0,1,2 \\
& \mathrm{H}_{2}+\mathrm{e} \rightarrow \mathrm{H}+\mathrm{H}+\mathrm{e} \\
& \mathrm{PH}_{3}+\mathrm{H} \rightarrow \mathrm{PH}_{2}+\mathrm{H}_{2}
\end{aligned}
$$

On the contrary, the residence time dependence, shown in fig. $2 \mathrm{~b}$, indicates that $\mathrm{PH}_{3}$ decomposition reaches a plateau value $(-20 \%)$ owing to the competition between $\mathrm{PH}_{3}$ decomposition and its formation and, hence, to the following partial chemical equilibrium (PCE): 


$$
\mathrm{PH}_{3} \rightleftarrows \mathrm{P}+3 / 2 \mathrm{H}_{2}
$$

Among all plasma products, $\mathrm{PH}$ radicals and $\mathrm{H}$-atoms are particularly important as they can promote the TMI decomposition [3] and the carbon removal from the growing epilayers [4], through processes:

$$
\begin{aligned}
& \mathrm{CH}_{3} \text { (ads) }+\mathrm{H} \rightarrow \mathrm{CH}_{4} \uparrow \\
& \mathrm{CH}_{3} \text { (ads) }+\mathrm{PH}_{\mathbf{X}} \rightarrow \mathrm{CH}_{3} \mathrm{PH}_{\mathbf{X}} \uparrow \\
& \mathrm{CH}_{3} \text { (ads) }+\mathrm{PH}_{\mathbf{X}} \rightarrow \mathrm{PH}_{\mathrm{X}-1}+\mathrm{CH}_{4} \uparrow \\
& \mathrm{InCH}_{3} \text { (ads) }+\mathrm{PH} \rightarrow \mathrm{InP}+\mathrm{CH}_{4} \uparrow
\end{aligned}
$$

where the desorption of $\mathrm{CH}_{3}$ radicals is favoured by both $\mathrm{H}$ - atoms and $\mathrm{PH}_{\mathbf{X}}$ radicals, while $\mathrm{PH}_{\mathbf{X}}$ radicals directly promote the InP deposition (see eq. 8). Thus, the control of $\mathrm{PH}$ and $\mathrm{H}$ amounts and, hence, of the plasma parameters is determinant for the ongoing surface process. But, the true values of $\mathrm{PH}_{\mathbf{X}}$ and $\mathrm{H}$ densities at the substrate position depend, besides the formation in the plasma phase (eqs. 1-3), on the dIsappearance processes in the downstream region, where the following recombination processes are effective:

$$
\begin{aligned}
& \mathrm{H}+\mathrm{H}+\mathrm{H}_{2} \rightarrow \mathrm{H}_{2}+\mathrm{H}_{2} \\
& \mathrm{PH} \stackrel{\mathrm{H}}{\rightarrow} \mathrm{PH}_{2} \stackrel{\mathrm{H}}{\rightarrow} \mathrm{PH}_{3} \\
& \mathrm{PH}_{2}+\mathrm{PH}_{2} \rightarrow \mathrm{P}_{2} \mathrm{H}_{4}
\end{aligned}
$$

The $\mathrm{H}$ atom wall recombination process, $\left(\mathrm{H} \stackrel{\text { wall }}{\longrightarrow} 1 / 2 \mathrm{H}_{2}\right)$ has been found to be uneffective under present experimental conditions [21]. Nevertheless, the estimation of $\mathbf{H}$-atom and $\mathbf{P H}_{\mathbf{X}}$ radical densities, at the substrate position in the downstream of, respectively, $\mathrm{H}_{2}$ and $\mathrm{PH}_{3}-\mathrm{H}_{2}$ plasmas, has been done, for $\mathrm{H}$ atoms, on the basis of etching rate measurements of a phosphorus film and, for $\mathrm{PH}_{\mathbf{X}}$ radicals, through measurements of the phosphorus deposition rate.

\subsection{InP deposition and material characterization}

The effect of $\mathrm{PH}_{3}$ plasma decomposition on the InP growth kinetics has been evaluated, at fixed deposition temperature, through the analysis of the growth rate profile as a function of $\mathrm{PH}_{3}$ molar fraction $\left(\chi_{\mathrm{PH}_{3}}\right)$ in the gas feed. The resulting data are included in fig.3, which illustrates the effect of the plasma preactivation.

From the figure, it comes out that, at high V/III ratio (150 - 300), the growth rate is almost independent on $\chi_{\mathrm{PH}_{3}}$ and is mainly determinated by TMI partial pressure [22]. Under conditions of very low V/III ratio $(<50)$, and without plasma preactivation, non stoichiometric InP epilayers are grown and, correspondently, the growth rate increases. The effect of the plasma is double: on one side, at low V/III ratio, it allows the deposition of stoichiometric InP epilayers; on the other side, at high V/III ratio, it induces an increase in the growth rate [25]. Both these phenomena result from the much higher density of phosphorus active species present at the growth interface under plasma preactivation conditions. 


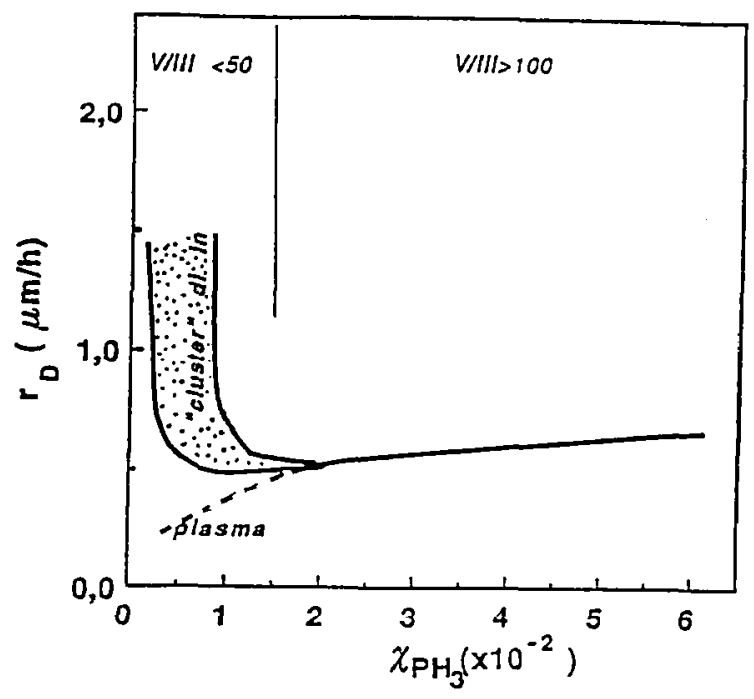

Figure 3: Deposition rate of InP films ys $\mathrm{PH}_{3}$ molar fraction in the TMI- $\mathrm{PH}_{3}-\mathrm{H}_{2}$ gas mixturc. Dashed line is for the effect of the $\mathrm{PH}_{3}$ plasma preactivation. Shadowed area is for the deposition of InP film with metalic indium droplets. (Other experimental conditions: $\mathrm{T}=550^{\circ} \mathrm{C}, \mathrm{P}=2$ torr, gas flow rate $=500 \mathrm{sccm}$, r.f. power $=20$ watt).

The presence of different chemical environments near the growth surface, depending on the V/III ratio, substrate temperature and on $\mathrm{PH}_{3}-\mathrm{H}_{2}$ plasma activation, has been revealed by MS analysis. MS data for some typical deposition experiments are listed in Tab. I in terms of ion peak intensities of the most significant $\mathrm{P}$-species, normalized to that of the $\mathrm{PH}_{3}{ }^{+}$pcak in the feed.

Table I: Mass spectrometric data for some InP deposition experiments with and without PH3 plasma preactivation, and at different V/III ratio and deposition temperature.

\begin{tabular}{|c|c|c|c|c|c|c|c|}
\hline & & \multicolumn{6}{|c|}{ MS RATIO I ${ }^{+} / I^{\circ}\left(\mathrm{PH}_{3}{ }^{+}\right)$} \\
\hline \multicolumn{2}{|c|}{$\begin{array}{lr}\text { EXPERIMENTAL RUN } \\
\text { V/III } & \mathrm{Tg}\left({ }^{\circ} \mathrm{C}\right) \\
\end{array}$} & $\mathrm{PH}_{3}{ }^{+}$ & $\operatorname{InPH}_{3}{ }^{+}$ & $\mathrm{P}\left(\mathrm{CH}_{3}\right)^{+}$ & $\mathrm{P}\left(\mathrm{CH}_{3}\right)_{2}^{+}$ & $\mathbf{P}_{2} \mathrm{H}_{4}^{+}$ & $\mathbf{P}_{4}^{+}$ \\
\hline 300 & 550 & 0.5 & $1 \cdot 10^{-4}$ & $8 \cdot 10^{-4}$ & - & $4 \cdot 10^{-4}$ & $9 \cdot 10^{-4}$ \\
\hline 150 & 600 & 0.47 & - & $3 \cdot 10^{-3}$ & - & $2 \cdot 10^{-3}$ & $2 \cdot 10^{-3}$ \\
\hline 20 & 550 & 0.55 & - & $6 \cdot 10^{-3}$ & $2 \cdot 10^{-3}$ & $8 \cdot 10^{-4}$ & $2 \cdot 10^{-4}$ \\
\hline 20 & 550 & 0.3 & - & $5 \cdot 10^{-3}$ & - & $1 \cdot 10^{-2}$ & $2 \cdot 10^{-3}$ \\
\hline
\end{tabular}

It can be observed that under plasma activation condition (\# InP8) the unreacted $\mathrm{PH}_{3}$ amount is lower than that measured for conventional deposition (\# InP7), i.e. the $\mathrm{PH}_{3}$ decomposition is equal to $70 \%$ and $45 \%$ with and without plasma, respectively. Also, a slight increase of the $\mathrm{PH}_{3}$ decomposition degree is measured with a temperature increase (see \# InP2, InP6). As for P-decomposition products, the formation of biphosphine, $\mathrm{P}_{2} \mathrm{H}_{4}$, and phosphorus, $\mathrm{P}_{4}$, increase with both temperature (\# InP2, InP6) and plasma activation (\# InP7, InP8). Moreover, the following situations can be distinguished: 
i) the ion fragment $\mathrm{InPH}_{3}+$ appears only for the experiment \# InP2, i.e. at very high V/III ratio $(-300)$. This ion fragment can be related to the presence of $\mathrm{Me}_{3} \mathrm{InPH} \mathrm{IH}_{3}$ adduct in gas phase.

ii) methylphosphines formation increases with a V/III ratio decrease and, in particular, the dimethylphosphine $\left(\mathrm{P}\left(\mathrm{CH}_{3}\right)_{2}{ }^{+}\right)$is present at very low V/III ratio (\# InP7). The methylphosphines formation can be correlated to the low availability of $\mathrm{H}$-atoms at the growth surface, so as the $\mathrm{CH}_{3}$ desorption process of equation (6) prevales on that of equation (5). The presence of dialchylphosphine, subtracting active phosphorus from the growing InP surface, causes the growth of non stoichiometric material, as confirmed by SEM-EDS joined measurements (\# InP7) revealing the presence of metallic indium droplets. On the contrary, when in presence of large amount of $\mathrm{H}$ atoms at the growth surface, as in the case of plasma activated process (see \# InP8), the dimethylphosphine disappears, the availability of active phosphorus at the growth surface increases, and stoichiometric material is obtained even at low V/III ratio.

As regards the material characterization, X-ray diffraction (XRD), spectroscopic ellipsometry (SE) and photoluminescence measurements have been performed on some typical samples deposited with (\#InP8) and without (\# InP6) plasma preactivation. Samples produced without plasma and under condition of very low V/III ratio (\# InP7) are not interesting as they are no: stoichiometric, In-rich epilayers.

Figure 4 shows the XRD spectra of \#InP6, \#InP8 samples and, for a comparison, of the (100) InP substrate. The $X$-ray diffraction peaks are centered at the same Bragg angle $\left(\Theta=31.57^{\circ}\right)$, so indicating the epitaxial (100) oriented nature of the deposited InP epilayers. In addition, the narrow half width evidences the high cristallinity of the InP6 film, whereas the broader features, characterizing the XRD peak of the sample \#InP8, indicates some structural disorder. In the latter case, the presence of InP microcluster with a slight different lattice constant is supposed. The origin of these microclusters has not been established, but, in the opinion of the present authors, it could be related to the presence of hydrogen in the material bulk.

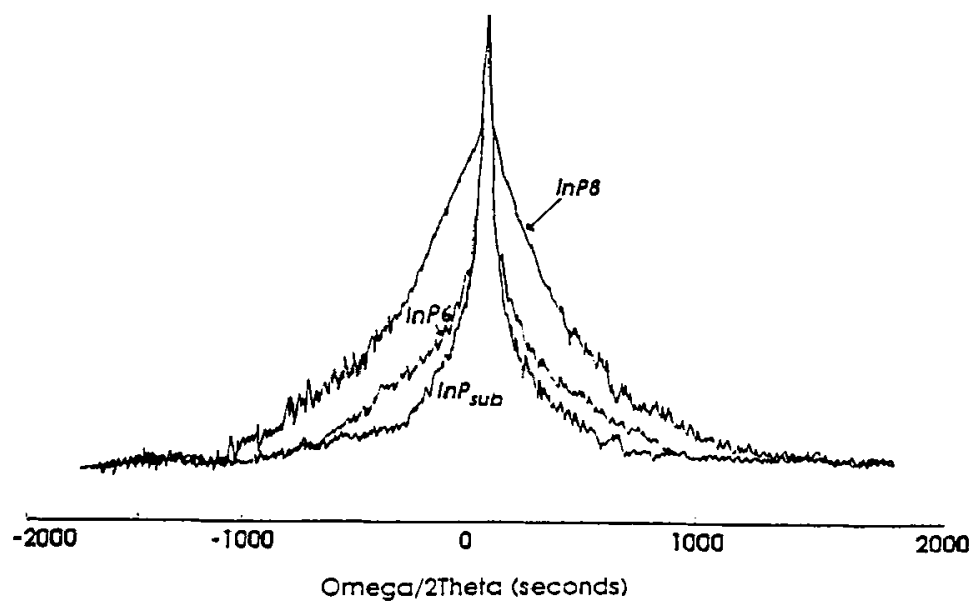

Figure 4: X-ray diffraction peaks for InP film deposited (a) without and (b) with $\mathrm{PH}_{3}$ plasma preactivation. The peak of the (100) InP substrate is shown for comparison.

Figure 5 shows the SE spectra of the imaginary part, $\varepsilon_{i}$, of the pseudodielectric function for the InP epilayers deposited under conditions of \# InP2, \# InP6, and \# InP8 experiments. The inset shows the thickness and composition values of each layer as obtained by the multilayer BEMA model [23] used for the fit of the experimental $\varepsilon_{\mathrm{i}}$ curves. 


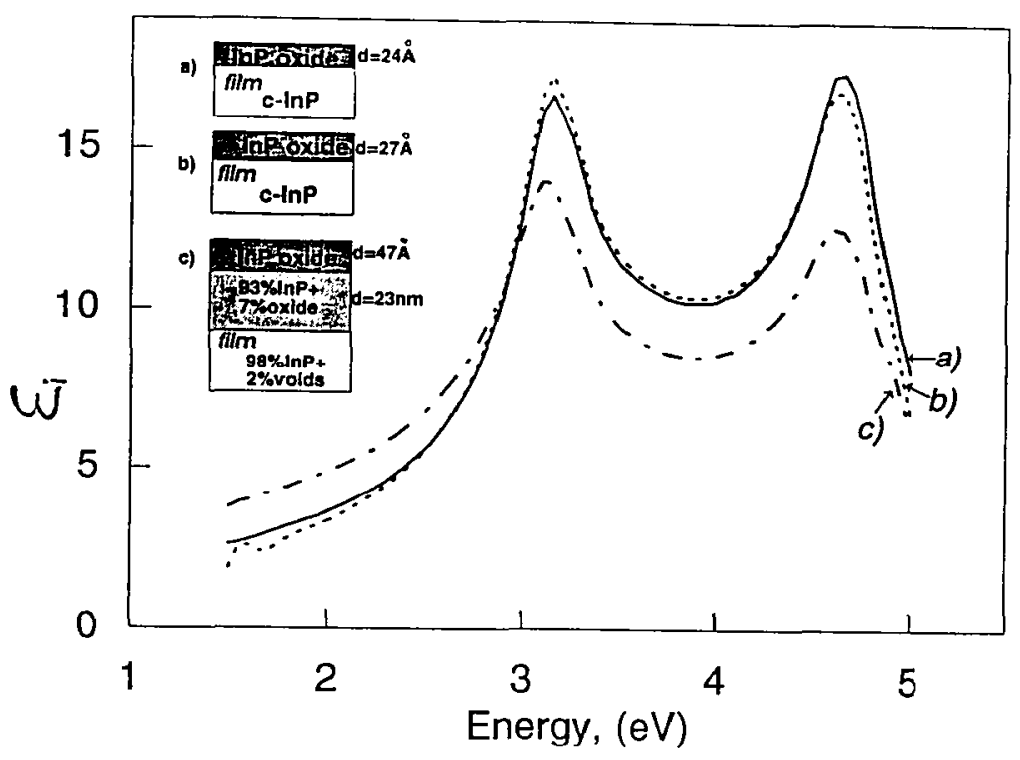

Flgure 5: $\varepsilon_{\mathrm{i}}$ ellipsometric spectra vs energy for InP epilayers deposited from experiments (a) \#InP8-plasma, (b) \#InP6 and (c) \#InP2 (see Tab.I).

The most important feature is the lower oxide layer thickness (24 $\AA$ ) for the InP8-plasma sample than that for samples deposited under conventional conditions (\# InP2, \# InP6). The formation kinetics of the native oxide layer can be used to speculate on the effectiveness of $\mathrm{H}_{2}-\mathrm{PH}_{3}$ plasma in passivating and stabilizing the InP surface [24]. In addition, the sample (\# InP2) deposited at high V/III ratio $(=150)$ and low temperature $\left(550^{\circ} \mathrm{C}\right)$ shows a complex multilayer structure on a disordered InP epilayer film which includes $2 \%$ of voids.

The goodness of the InP epilayers can also be evaluated by optical properties such as refractive index, $n$, and absorption coefficient, $\alpha$, which can be derived by SE measurements. Figure 6 shows the $\mathrm{n}$ and $\alpha$ values vs energy for the same samples of figure 5 and for a clean and well-ordered c-InP sample.
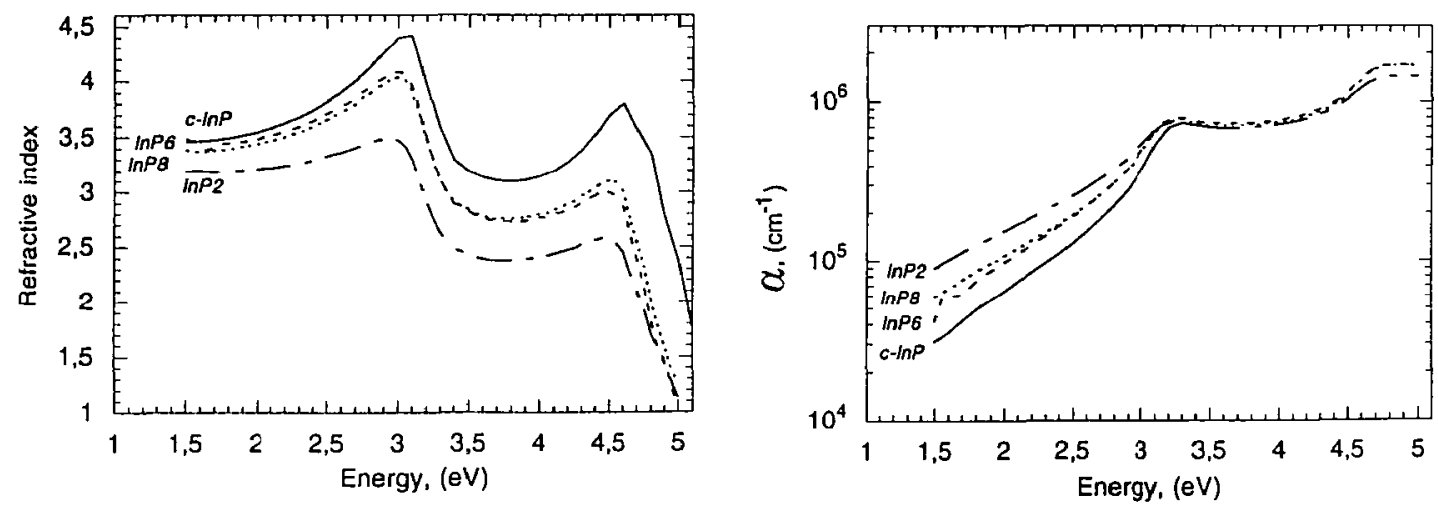

Figure 6: Refractive index, $\mathrm{n}$, and optical absorption coefficient, $\alpha$, vs energy for the same InP films of fig.5. The literature data of a clean and well-ordered c-inP film are also shown. 
The higher the epilayer quality, the higher the refractive index and the lower the absorption coefficient. Again, the optical quality of the InP8-plasma epilayer is comparable to that of the best film deposited without plasma (\# InP6).

Photoluminescence measurements, performed at $2 \mathrm{~K}$, have revealed for the InP8- plasma film a PL efficiency five times higher than that of InP6, which is, in turn, fifty times higher than that of the c-InP substrate. The PL efficiency for plasma deposited samples remains higher than that for samples deposited without plasma, even at room temperature.

\section{Acknowledgements}

The authors wish to thank dr. L. Tapfer (PASTIS/CNRSM) for the XRD measurements and fruitful discussion.

\section{References}

[1] G.B. Stringfellow, Organometallic Vapor Phase Epitaxy:Theory and Practice (Academic Press Inc., 1989).

[2] S.W. Choi, K.J. Bachmann, G. Lucovsky, J. Vac. Sci. Technol. A, 11(3) (1993) 626.

[3] S.W. Choi, G. Lucovsky, K.J. Bachmann, J. Vac. Sci. Technol. B, 10(3) (1992) 1070.

[4] T. Sugino, K. Kawarai, M. Maeda, J. Shirafuji, J. Crys. Growth, 139 (1994) 15.

[5] M Behet, A. Brauers, P. Balk, J. Cryst. Growth, 107 (1991) 209.

[6] S. Sakai, S. Yamamoto, M. Umeno, Jap. J. Appl. Phys., 25(8) (1986) 1156.

[7] U. Sudarsan, N.W. Cody, T. Dosluogolu, R. Solanki, J. Crys. Growth, 94 (1989) 978.

[8] H. Takei, T. Hamada, T. Hariu, J. Crys. Growth, 115 (1991) 309.

[9] M. Behet, A. Brauers, H. Luth, P. Balk, J. Crys. Growth, 107 (1991) 209.

[10] S.F. Fang, T. Hariu, J. Vac. Sci. Technol. A, 9(4) (1981) 2253.

[11] R. Schutz, H.L. Hartnagel, Int. J. Electronics, 67(2) (1989) 233.

[12] G. Bruno, M. Losurdo, P. Capezzuto, J. Vac. Sci. Technol. A, 13(2) (1995) 1.

[13] A.J. Nelson, S. Frigo, D. Mancini, R. Rosenberg, J. Appl. Phys., 70(10) (1991) 5619.

[14 ]P.G. Hofstra, D.A. Thompson, B.J. Robinson, R.W. Streater, J. Vac. Sci. Technol. B, 11(3) (1993) 985.

[15] D.E. Aspnes, R. Bhat, C. Caneau, E. Colas, L.T. Florez, S. Gregory, J.P. Harbison, I. Kamiya, V.G. Keramidas, M.A. Koza, M.A.A. Pudensi, W.E. Quinn, S.A. Schwarz, M.C. Tamargo, H. Tanaka, J. Crys. Growth, 120 (1992) 71.

[16] B. Drevillon, E. Bertran, P. Alnot, J. Oliver, M. Razeghi, J. Appl. Phys, 60(10) (1986) 3512.

[17] C.A. Larsen, G.B. Stringfellow, J. Crys. Growth, 75 (1986) 247.

[18] N. I. Buchan, C.A. Larsen, G.B. Stringfellow, J. Crys. Growth, 92 (1988) 605.

[19] J.A. McCaulley, R.J. Shul, V.M. Donnelly, J. Vac. Sci. Technol. A, 9(6) (1991) 2872.

[20] G. Bruno, M. Losurdo, P. Capezzuto, this conference.

[21] G. Bruno, M. Losurdo, P. Capezzuto, Appl. Phys. Lett., to be published.

[22] H. Heinecke, A. Brauers, H. Luth, P. Balk, J. Crys. Growth, 77 (1986) 241.

[23] D. A. G. Bruggemann, Ann. Phys., 24 (1985) 636.

[24] R.W. Glew, A.R. Adams, C.G. Crookes, P.D. Greene, S.N. Holmes, S.A. Kitching, P.C. Klipstein, D. Lancefield, R.A. Stradling, R.A. Woolley, Semicond. Sci. Technol. 6 (1991) 1088. 